\title{
Challenges of Measuring Graduation in Rwanda
}

\author{
Rachel Sabates-Wheeler, Samantha Yates, Emily Wylde and \\ Justine Gatsinzi
}

\begin{abstract}
Rwanda demonstrates how a process of community consultation and participation is able to identify and rank community members according to 'social poverty', drawing on the Ubudehe tradition which is considered a strength of Rwanda's social fabric. However, with the Ubudehe categorisation now the basis for determining eligibility to a range of social benefits, the process has come under some strain. This article highlights two issues related to targeting and graduation: (1) the difficulty in identifying the poor/non-poor and ranking the population using community participatory techniques; and (2) the sensitivity of eligibility criteria and graduation thresholds to different targeting modalities. Our primary interest is to establish whether improvements for identifying the poor and non-poor can be made without undermining community ownership and what these improvements would look like. This will be useful for policymakers in Rwanda as the new five-year development strategy places importance on graduating households out of extreme poverty.
\end{abstract}

\section{Introduction}

Identifying the poorest for selection into social transfer programmes is a perennial challenge facing programme implementers, and a major point of debate in the social protection literature. Targeting describes a process for identifying households or individuals who are defined as eligible for resource transfers, thereby screening out those who are defined as ineligible. Achieving this simple objective is one of the most challenging aspects of implementing social transfer programmes, and typically requires trade-offs to be made between targeting accuracy and targeting costs (Coady, Grosh and Hoddinott 2004). Accurate targeting is expensive and time-consuming, yet if targeting is not done well or coverage is too broad it can be extremely wasteful of scarce resources and may undermine programme effectiveness (Barrientos and Niño-Zarazúa 2011).

With limited public resources (as is the case in Rwanda), targeting of social benefits (as opposed to universal coverage) is a necessity. In Rwanda poverty is 'objectively' measured through a living standards measurement survey (Enquete Integrale des Conditions de Vie des Menages, or EICV), which measures household consumption, and the Demographic and Health Survey (DHS), which measures asset poverty. Rwanda also captures 'social' poverty through a social categorisation process, Ubudehe, which has much in common with participatory poverty assessment approaches. This social categorisation performed within the community has become the basis for determining household eligibility for a whole range of social benefits.

In this article we reflect on: (1) Rwanda's history of using community-based social-economic mapping as the basis for targeting access to social benefits and services; (2) the current process of reviewing this approach; and (3) whether a new approach will improve measurement and monitoring of graduation from poverty. We do this to draw lessons on the effectiveness of different poverty identification methods and to inform the design of targeting and the measurement of graduation in future social protection programming. We show that in the Rwandan case, while empirically a 'balanced scorecard' approach to identifying the poor(est) clearly improves targeting efficiency, in practice this must be combined with some community involvement, building on the Ubudehe tradition. 
Identifying the poor/non-poor, and amongst them the poorest, and thus determining eligibility for social benefits for members of the population is critical to supporting the Government of Rwanda's graduation vision; because identification enables more accurate monitoring of changes in welfare, and thus graduation trajectories. This article draws on recent and ongoing empirical analysis and vibrant discussions within the social protection sector in Rwanda.

\section{The Ubudehe system and its evolution into a targeting mechanism ${ }^{1}$}

Shah (2011) provides a detailed description of the history and role of Ubudehe in his doctoral work on the subject. He reviews the role and potential of social mapping and participatory statistics in Ubudehe, a Government of Rwanda-led policy and approach initiated in 2001 'designed to increase the level of institutional problem solving capacity at the local level by citizens and local government by putting into operation the principles of citizen participation through collective action' (MINECOFIN 2003: 4).

The majority of literature and journalistic pieces refer to Ubudehe as a 'revived traditional practice' (Ensign and Bertrand 2010). Indeed the literal origins of the word refer to it being a Rwandan practice and cultural value of working together to solve problems, traditionally digging fields collectively before the rains came and the planting season began. It is considered a 'home-grown initiative', aiming to nurture citizen participation in development through collective action, with roots in the Rwandan tradition where people used to sit together to analyse their problems and help each other in problem-solving at a local level.

'However, the Ubudehe of post-genocide Rwanda is more sophisticated and complex than most analysts seem to suggest, drawing from a combination of theories and a pragmatic political context' (Shah 2011: 1). Pragmatically, it was conceived by 'reformists' within the Rwandan government and their development partners, emerging in its contemporary form in 2001, amidst several opportune conditions and collaborations. The reformists argued a case for participatory democracy and achieved a consensus where the aim was to:

give the floor and freedom to the people so that they can talk about their problems and how they can be solved. A Rwandan citizen has never been given the floor, he has always been waiting for instructions from his superiors and he has always been guided by them. It is necessary, therefore, to look for 'mechanisms' of giving the floor to people (cited in Shah 2011: 57).

It was within this context of consensus around looking for mechanisms of giving 'floor' to the people that Ubudehe emerged.

At the same time as space opened up for developing mechanisms to enable increased participation at the local level in Rwanda, international development institutions were promoting accountability to the poor through Poverty Reduction Strategy Papers (PRSPs) and decentralisation as a 'good governance' strategy. Shah argues that:

the rhetoric behind donor discourses of PRSPs as a mechanism to afford citizens the opportunity to participate in articulating their needs and preferences dovetailed neatly into the vision of participatory democracy envisaged. What the development trend of PRSPs did was to coincidentally bring together a group of actors from within government, donor and civil society, who would become the core protagonists in conceiving, designing and driving Ubudehe (Shah 2011: 58-9).

Indeed, within Rwanda's first PRSP, Ubudehe is seen as modernising a traditional concept, adapted to 'build on the positive aspects of this history and complement it with modern participatory techniques, which have proven their worth in community development... It sets out to strengthen democratic processes and governance starting from people's aspirations, ability and traditions' (VUP 2011: 13).

Ubudehe as an approach to poverty reduction started as a pilot project in Butare, southern Rwanda, as part of the Participatory Poverty Assessment to provide background data for the PRSP. Once the PRSP was adopted, Ubudehe was rolled out nationwide (as a means of categorisation and as a programme of community development). Since 2001, through Participatory Poverty Assessment methodology at village level, the programme has been collecting information 


\section{Category name and number Characteristics}

\begin{tabular}{|c|c|}
\hline $\begin{array}{l}1 \text { Umutindi Nyakujya } \\
\text { (Those in Abject Poverty) }\end{array}$ & $\begin{array}{l}\text { Destitute. Need to beg to survive. Have no land or livestock. Lack adequate } \\
\text { shelter, clothing and food. Fall sick often and have no access to medical } \\
\text { care. Children are malnourished and they cannot afford to send them to } \\
\text { school. Not respected. Discriminated against. }\end{array}$ \\
\hline $\begin{array}{l}2 \text { Umutindi } \\
\text { (The Very Poor) }\end{array}$ & $\begin{array}{l}\text { The main difference between the Umutindi and the Umutindi Nyakujya is that } \\
\text { people in this group are physically capable of working on land owned by others, } \\
\text { although they themselves have either no land, or very small landholdings, } \\
\text { and no livestock. They suffer from low harvests and also have no access to } \\
\text { health care or schooling }\end{array}$ \\
\hline $\begin{array}{l}3 \text { Umukene } \\
\text { (The Poor) }\end{array}$ & $\begin{array}{l}\text { These households have some land and housing. They live on their own } \\
\text { labour and produce, though they have no savings; they can eat, even if the } \\
\text { food is not very nutritious. However, they do not have a surplus to sell in } \\
\text { the market, their children do not always go to school and they often have } \\
\text { no access to health care. }\end{array}$ \\
\hline $\begin{array}{l}4 \text { Umukene Wifashije } \\
\text { (The Resourceful Poor) }\end{array}$ & $\begin{array}{l}\text { Households in this group share many of the characteristics of the Umukene but } \\
\text { in addition they have small ruminants and their children go to primary school. } \\
\text { They have a few animals and petty income to satisfy a few other needs. }\end{array}$ \\
\hline $\begin{array}{l}5 \text { Umukungu } \\
\text { (The Food Rich) }\end{array}$ & $\begin{array}{l}\text { People in this group have larger landholdings with fertile soil and enough to } \\
\text { eat. They have livestock, often have paid jobs and can access health care. They } \\
\text { employ others on their own farms and at times have access to paid } \\
\text { employment. They have some savings. }\end{array}$ \\
\hline $\begin{array}{l}6 \text { Umukire } \\
\text { (The Money Rich) }\end{array}$ & $\begin{array}{l}\text { People in this group have land and livestock and often have salaried jobs. They } \\
\text { have good housing, often own a vehicle, and have enough money to lend and } \\
\text { to get credit from the bank. Many migrate to urban centres. }\end{array}$ \\
\hline
\end{tabular}

Source Shah (2013: 54); MINECOFIN (2003) and Joseph (2006).

on the social and economic status of the population (national categorisation has taken place in 2001, 2005-6, 2007-8 and 2012). In the initial mapping through this Ubudehe process, facilitators (local and international) determined that, from all the local understandings of poverty and wealth and status, six categories could be used to stratify the entire population in relation to its living conditions. These categories are known as 'Ubudehe categories' and are named in Kinyarwanda as: Umutindi Nyakujya, Umutindi, Umukene, Umukene Wifashije, Umukungu and Umukire. Table 1 sets out these categories and their characteristics.

The English translation does not do justice to the metaphorical nature of some of the characteristics. For example, for households in category 1, umutindi nyakujya, the literal translation of the characteristics captures the misery of extreme poverty; for instance, 'doesn't even have nails to scratch himself with' and 'death would be a relief'.
Whether the category characteristics are still meaningful, given Rwanda's strong progress on poverty reduction and the shifts in the profile of poverty, is a pertinent question, and one we address here. Since the first Ubudehe exercise the proportion of the population living in 'objective' consumption poverty has reduced from 59 per cent to 45 per cent, the proportion living in extreme poverty has reduced from 40 per cent to 24 per cent, and the depth of poverty has reduced (the poverty gap was 41 per cent in 2000/1 and 33 per cent in 2010/11; the extreme poverty gap was 34 per cent and 26 per cent respectively). ${ }^{2}$

The extent to which these Ubudehe characteristics are helpful in distinguishing between the poor and non-poor is also a pertinent question. Since the first Ubudehe exercise access to basic education has improved, with school enrolment now reaching 96.5 per cent. ${ }^{3}$ Access to health care has also improved (reflected in 
improvements in the under-five mortality rate which has reduced by two-thirds between 2000 and $2010^{4}$ and improvements in life expectancy from 51 to 64 years over the same period $)^{5}$ as a result of a series of health reforms including the roll-out of community health centres, underpinned by a cadre of community health workers and a programme of community health insurance. Furthermore, housing policies passed and implemented in the last ten years means that 'lack of shelter' is not necessarily an appropriate and widespread indicator of poverty any more.

As the nature of poverty has shifted in Rwanda since 2001, so too has the process of Ubudehe categorisation. While the main advantage of community-based targeting is that local residents have personal knowledge of their neighbours, which outsiders do not, the main risk is that the process may be dominated by local elites who capture the benefits and exclude socially marginalised groups (see Sabates-Wheeler, Lind and Hoddinott 2013, for evidence on local capture). On the other hand, problems may emerge because Ubudehe criteria are not specific or 'objective'/easily measurable. This means that there may be a subjective, 'loose' or locally adapted interpretation of the criteria making them difficult to apply consistently across different localities and regions or over time. Given that the national Ubudehe system provides the foundation for determining eligibility for a whole slew of social benefits (including the Vision 2020 Umurenge Programme (VUP) (social protection), health insurance, tertiary scholarships, waiving of land registration fees), the quality and consistency of this categorisation process is a key determinant of the effectiveness and efficiency of targeting and of programme outcomes - graduation being a pertinent one. Community-based social mapping (which the Ubudehe system uses) becomes community-based targeting used for allocating resources. This form of targeting delegates or devolves beneficiary selection to community members.

While in theory the socioeconomic mapping happens in a highly participatory and democratic way, over time the process has become increasingly administrative. Villages no longer produce social maps, rather data collected by the Ubudehe committee are entered manually into a table and processed by computer. Recent research (Berglund 2013) suggests that the process has become top-down and technocratic. As a result, people are not always aware as to why they are in a specific category or what defines that category.

A recent study supported by the Rwandan Civil Society Platform (Sentama 2014) highlights a number of shortcomings in the way that the Ubudehe process is now being carried out. Of the perceived process of Ubudehe categorisation, 68.8 per cent of respondents from a sample of VUP beneficiary and non-beneficiary households said that they thought it was 'not well done' or 'done badly'. From these, many said that they did not fully take part in the categorisation process, and some accuse the local authorities of deciding unilaterally about whom to place in one category or another (op. cit.: 23). Respondents also expressed concern about indicators:

\section{The indicators followed to categorise people in Ubudehe program were not clear. The [officials in charge of Ubudehe] could find that you have a house and then classify you in the category they want without asking you whether the house is yours or what: not everyone was consulted (a citizen of Rwezamenyo sector - Sentama 2014: 24).}

When asked how the current Ubudehe categorisation relates to the traditional practice of Ubudehe, the findings were startling. The majority of respondents (63.6 per cent) said that there is no linkage between the two and 32.8 per cent saw some connection despite shortcomings.

Before [in traditional Ubudehe] people used to support mutually in solidarity; it was solidarity in farming or building households; now categories under Ubudehe program do not at all refer to this solidarity; it is individual work in loneliness (a citizen of Rwezamenyo sector - Sentama 2014: 26).

Finally, from 250 households interviewed, 83.6 per cent stated that they were very dissatisfied with the category in which they had been placed. Only 6 per cent indicated that they were satisfied or very satisfied with their categorisation. An obvious reason for the high levels of dissatisfaction was related to the very low levels of farmland, shelter and livestock owned by many of the households. Many category 3 households (62 per cent were in category 3) stated that their low asset levels qualify them for category 2 (23 per cent of the 


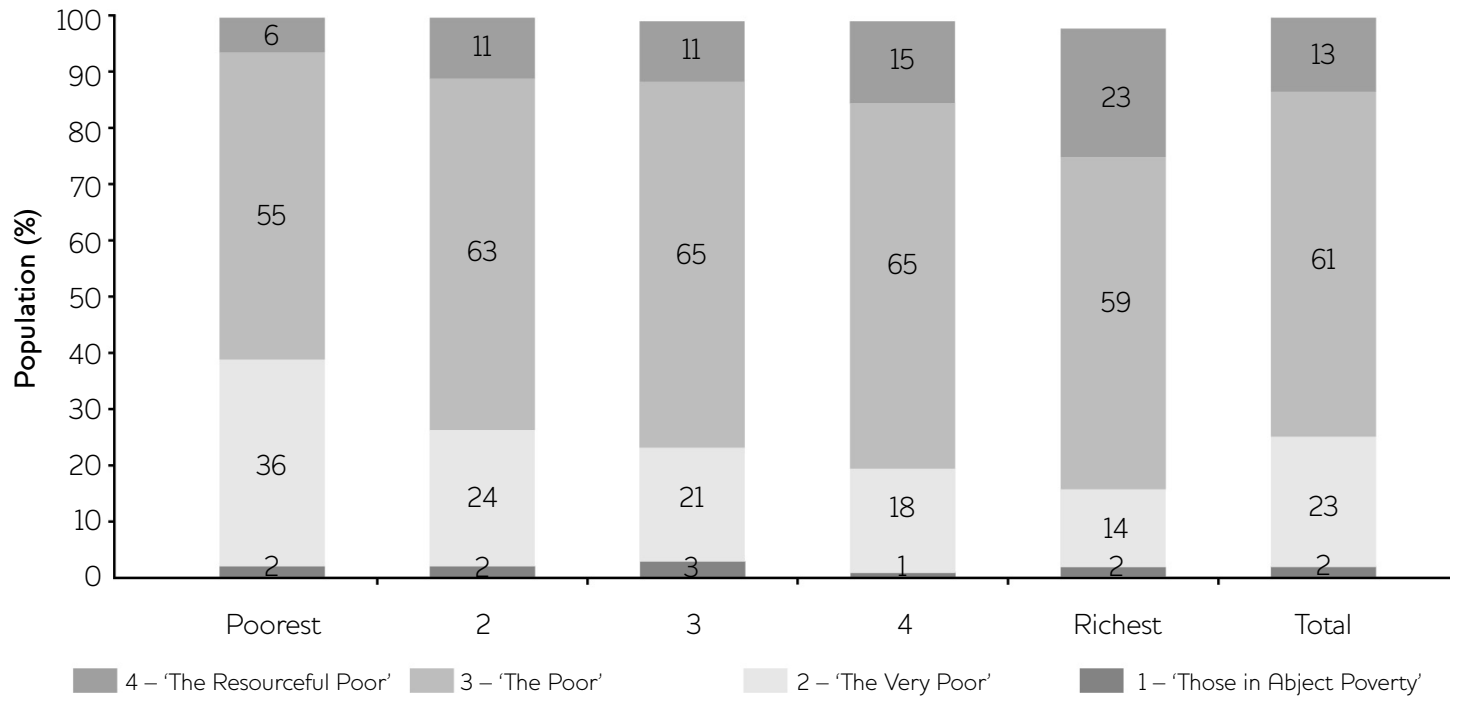

Source Authors' own.

sample), yet they 'have been put' unfairly in category 3. This finding, together with qualitative work, questions the participatory and collective action ethos of the Ubudehe process.

Over time, as noted above by recent research, the Ubudehe categorisation process has become increasingly ad hoc and less transparent. The nature and profile of poverty have clearly changed since Ubudehe categorisation first took place. In the next section we draw on new analysis to consider how well Ubudehe identifies the poor and amongst them the poorest.

\section{The problem: how well does the Ubudehe system identify the poor?}

Each February the president of Rwanda leads an annual leadership retreat to take stock of progress and challenges and set priorities for the coming year. The 2014 leadership retreat commitments include a commitment to 'expedite revisions to Ubudehe', given the increasing evidence that the Ubudehe categorisation process is under strain. Government of Rwanda policy papers have captured evidence of interest groups mobilising locally for re-categorisation of their client group into categories 1 and 2 to ensure access to social protection benefits (MINALOG 2012) - a variation of 'elite capture' discussed above; citizen complaints about targeting decisions based on Ubudehe status for education bursaries led to the convening of a dedicated Ministerial Commission to resolve complaints in 2013; and several technical reports testify to challenges with using Ubudehe to target benefits (VUP 2011). New evidence, which we present below, highlights that Ubudehe is not effectively categorising the poor.

In order to objectively assess the extent to which Ubudehe status correlates with consumption poverty measures, we were able to match households in the EICV3 national household survey with their Ubudehe status contained in the Ubudehe database. ${ }^{6}$ This matching allowed us to look at the distribution of Ubudehe status across consumption quintiles. In theory, there should be a strong correlation between consumption poverty and Ubudehe status, with those in the poorest quintile in particular (roughly corresponding to the extreme poor) making up the majority of Ubudehe categories 1 and 2. Instead, as Figure 1 shows, very few of the poorest households ( 2 per cent) were identified as Ubudehe category 1, and the richest quintile households were equally likely to be allocated that status as the poorest (indeed, it was fairly consistent across all consumption quintiles). Ubudehe category 2 does decrease with consumption quintile, but many of the richest are nevertheless included. The most frequent Ubudehe category is 3, with 61 per cent of the population allocated to it. ${ }^{7}$ 
Table 2 Lighting source and toilet type, by consumption quintile, rural

\begin{tabular}{|c|c|c|c|c|c|c|c|}
\hline \multicolumn{8}{|c|}{ Lighting source } \\
\hline Quintile & Electricity & Oil lamp & Firewood & Lantern & Battery & Other & Total \\
\hline Lowest & 2 & 10 & 41 & 15 & 21 & 17 & 19 \\
\hline Second & 1 & 13 & 20 & 22 & 23 & 15 & 20 \\
\hline Third & 6 & 18 & 18 & 25 & 22 & 16 & 21 \\
\hline Fourth & 15 & 27 & 14 & 25 & 22 & 27 & 23 \\
\hline Highest & 76 & 32 & 7 & 13 & 12 & 25 & 18 \\
\hline Total & 100 & 100 & 100 & 100 & 100 & 100 & 100 \\
\hline \multicolumn{8}{|l|}{ Toilet type } \\
\hline Quintile & Flush toilet & $\begin{array}{l}\text { Pit latrine } \\
\text { unimproved }\end{array}$ & $\begin{array}{l}\text { Pit latrine } \\
\text { improved }\end{array}$ & Other & No toilet & Total & \\
\hline Lowest & 1 & 17 & 23 & - & 29 & 19 & \\
\hline Second & 6 & 20 & 20 & 23 & 19 & 20 & \\
\hline Third & 6 & 21 & 23 & 50 & 19 & 21 & \\
\hline Fourth & 10 & 23 & 23 & 28 & 18 & 23 & \\
\hline Highest & 77 & 19 & 11 & - & 15 & 18 & \\
\hline Total & 100 & 100 & 100 & 100 & 100 & 100 & \\
\hline
\end{tabular}

Source: Authors' own.

This analysis suggests that 62 per cent of the extreme poor would be excluded from VUP since they are not in Ubudehe categories 1 or 2. At the same time, 2 per cent of the richest quintile are classified as Ubudehe category 1 and 14 per cent as Ubudehe category 2, meaning that 16 per cent of them would be eligible for VUP.

\section{How to identify the poor and the poorest}

Recognising the difficulties of the current Ubudehe approach in correctly identifying the poor, the Government of Rwanda moved quickly to think about a new classification system which will use both community processes of poverty identification and some objective indicators for identification as well as monitoring. Initial discussions have focused on a four-category system with a limited number of indicators per category. The indicators initially proposed included home ownership, for instance, where it was suggested that absence of home ownership or ability to rent would be a good identifier of the most poor. Other proposed indicators included livestock ownership, lighting source in the home and a simple asset index. In order to test whether these simple asset variables are indeed adequate for identifying the poor we take EICV3 data and look at the correlation between different assets with consumption poverty quintiles. Specifically, we look at the following variables: highest level of education in the household; type of lighting source; type of cooking fuel; type of toilet; type of wall; roof type; household durable assets; livestock ownership.

Table 2 presents a sample of this analysis showing the distribution of household construction and durables by quintile in rural areas (since poverty is largely rural). ${ }^{8}$ We can see that the variables are not strong predictors of poverty and therefore not appropriate for targeting or use as graduation indicators. For instance, while electricity use for lighting or flush toilet ownership is helpful for identifying the richest, most other variables do not provide sufficient variation across quintiles to be useful. The use of oil lamps or firewood for lighting do show reasonable trends across quintiles, but they are not sufficient for the purposes of identification. While not reported here, the same pattern exists for livestock 
ownership and other assets, such as beds, radios and bicycles.

These findings show, unsurprisingly, that asset approaches (of which this exercise is a type) are extremely difficult to apply to rural areas. ${ }^{9}$ As we found for Rwanda, variables either only separate out the richest quintile from the rest, or they are too evenly distributed across quintiles to be relevant. Unfortunately, there are simply no easily identifiable variables (or combination of variables) that would be able to clearly and accurately distinguish the poorest from those who are better off.

A possible alternative would be to construct an asset index that combines a few variables which show reasonable correlation to poverty by using factor analysis. However, from our analysis of asset index scores, we found that about half the population is allocated exactly the same score, making it impossible to sort the population into five equal quintile 'bins' against which we could compare asset quintile with consumption quintile. ${ }^{10}$

In fact, we found that 71 per cent of the poorest consumption quintile (roughly the extreme poor) are correctly allocated in the 47.5 per cent of asset scores nationally, but so are 25 per cent of the richest quintile and 40 per cent of the second richest. Also, if we were to use the lowest asset index group scores for targeting, only 27 per cent of beneficiaries would be from the poorest quintile and 24 per cent from the second poorest, while roughly half (the remainder) would be from those above the poverty line. This shows that even if there were enough budget to cover 47.5 per cent of the population in the bottom asset group, the index would not do a good job in targeting/identifying the poor.

This raises an interesting dilemma: trying to aim for simplicity (in the definition of variables and in the number used in the index) is likely to lead to large percentages of the population being scored exactly the same. This is not surprising given the large numbers of poor households in Rwanda, yet in order to allocate scarce resources, identify households for benefits and accurately monitor graduation trajectories, we need to be able to distinguish better between poor households in terms of their need. How then can we do this?

\section{Developing a simple scorecard methodology}

Given the obvious difficulties in using these basic indicators as a way to categorise households, we developed a simple scorecard methodology to test whether we can improve targeting efficiency. Proxy Means Tests (PMTs) are a scorecard-type of targeting, where a limited number of variables (ideally those that are easily recorded and verified) are used to determine eligibility. The steps in a PMT/scorecard are:

A regression model of the correlates of poverty is estimated. The PMT regression then provides the PMT scoring system, with the estimated coefficients serving as the weights for the scoring.

- PMT scores are then calculated for each household based on these weights. The PMT scores are essentially predicted values of consumption and provide a ranking of households over a population.

- For targeting purposes, households can be selected into a programme based on their PMT score, once a cut-off value of the score is determined.

Targeting efficiency, graduation trajectories and poverty impact of the PMT scoring system can then be evaluated, essentially by comparing how well the predicted values in the PMT score compare with actual consumption at different programme coverage levels. So for example, with a targeted coverage of 20 per cent, targeting efficiency measures the extent to which the PMT score accurately predicts whether a household's consumption is in the bottom two deciles.

\subsection{Findings}

\subsubsection{Identifying variables associated with poverty}

In order to decide which variables should be included in the regression/scorecard, it is important to understand which variables, together, are most associated with poverty. Looking at the distribution of different variables across consumption quintiles helps to provide a good picture of the characteristics of the poor versus those who are better off.

The following were identified as some of the most relevant variables: type of lighting source, type of cooking fuel, type of toilet, type of wall, roof type, household durable assets, and livestock. We also found that education (as proxied by the highest level of education in the household) was 


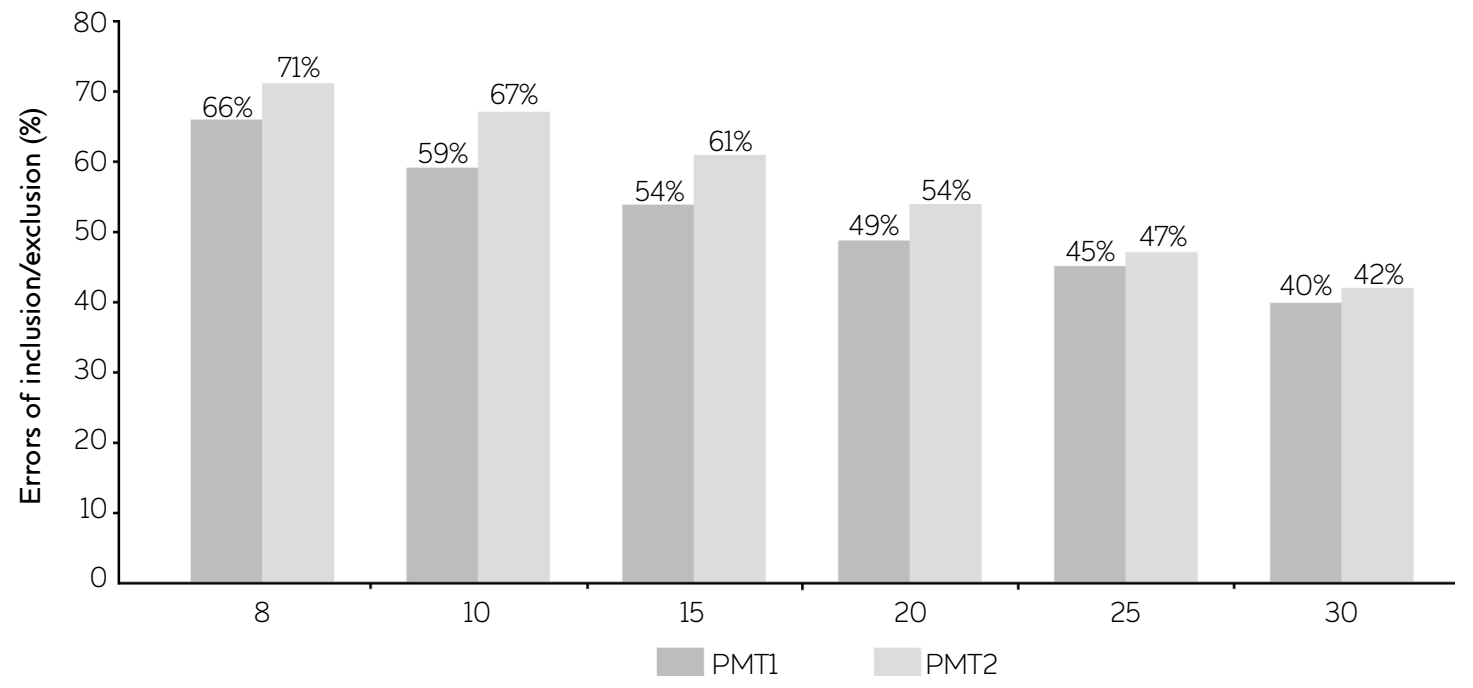

Source Authors' own.

correlated strongly to consumption quintiles. Those in the poorest quintile are far more likely to have had only some primary education (56 per cent compared to 23 per cent in the richest), while those in the richest are three times more likely to have had secondary education (11 per cent of the poorest quintile have a member with secondary education compared to 33 per cent of the richest).

\subsubsection{Regression results}

Two scorecard options were considered. The first includes more variables, while the second is a shortened version (keeping those variables with the more economically and statistically significant coefficients). The regressions, which use the $\log$ of per-adult equivalent consumption as the dependent variable, were run for each scorecard. ${ }^{11}$ The signs of the coefficients are as expected: higher levels of education are associated with higher consumption, while household size and number of children are associated with lower consumption. Households using electricity for lighting are better off than all other types of lighting, while those using charcoal for cooking fuel are better off than those using firewood.

Ownership of assets (livestock, radio, bed, bicycle, fridge) are all associated with higher consumption. Having a household member work in agricultural wage work is associated with lower consumption (as would be expected), while wage work in the non-farm sector and participation in some kind of household nonfarm enterprise (of any size, including microenterprise) is associated with higher consumption. The regressions both have a fairly high predictive power. ${ }^{12}$

\subsubsection{Errors of inclusion and exclusion}

Figure 2 shows errors of inclusion/exclusion by programme size and by the two scorecards. For a programme covering 8 per cent of the population (as expected based on the national scale-up of the existing programme), errors would be 66 per cent for PMT1, meaning 66 per cent of beneficiaries would be above the 8 th percentile in consumption. A programme reaching 10 per cent of the population would have errors of 59 per cent for PMT1, while one reaching 30 per cent (which would require substantially more financial resources) would have errors of 40 per cent. This pattern of decreasing errors by programme size is typical of PMT/scorecard approaches; the wider the net, the easier it is to make sure households are captured more accurately.

Errors are slightly higher under the shorter scorecard compared to the longer one, reflecting the loss of predictive power as a result of the removal of some variables. Nevertheless, the results are fairly consistent, suggesting that a shorter scorecard, which would be easier to implement, might be preferable even if there is a slight loss in terms of accuracy. 
Figure 3 Distribution of beneficiaries by consumption quintile, Ubudehe versus PMT options

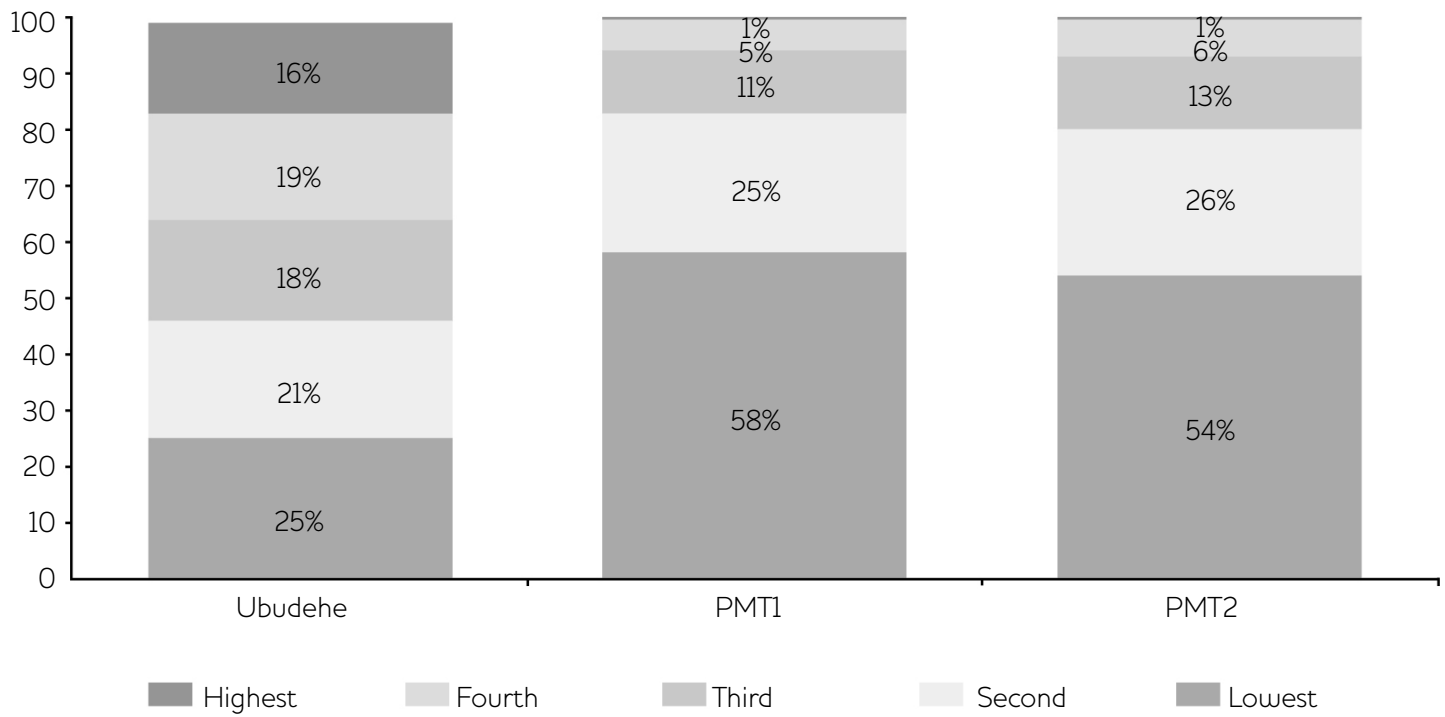

Source Authors' own.

Errors are not distributed evenly across the population, however, but are instead concentrated amongst the poor. We see from Figure 3 that 58 per cent of beneficiaries would be in the poorest consumption quintile, 25 per cent in the second, and 11 per cent in the third for PMT1. PMT2 is quite similar, with just slightly less in the first quintile and slightly more in the next three quintiles. Less than 1 per cent would be from the highest quintile in either option. This would be a marked improvement over the results found from current targeting (Figure 3, column 1), where only 25 per cent were in the first quintile, 21 per cent were in the second and over 16 per cent were in each of the three richest quintiles (as estimated by those households participating in VUP in the EICV3 sample).

The PMT/scorecard would be biased towards the extreme poor and the poor, so at a programme coverage of 10 per cent, 21 per cent of the poor and 31 per cent of the extreme poor would be covered. The overarching point here is that identification of the poor/non-poor is highly sensitive to the eligibility criteria and cut-offs chosen. This means that graduation thresholds and measurements of graduation pathways will be equally sensitive to this.

\subsubsection{Comparison with existing Ubudehe approach}

Data on actual VUP participation in the household survey (EICV3) exists, so we are able to compare the consumption poverty of actual VUP beneficiaries in EICV3 with potential beneficiaries of the PMT options, as shown in Figure 3. It is clear that the two PMT options would draw the majority of beneficiaries from the poorest consumption quintile, compared to just 25 per cent of existing VUP beneficiaries. PMT1 would draw 17 per cent of its beneficiaries from the top three quintiles, compared to 54 per cent of current VUP beneficiaries.

\subsubsection{Errors of exclusion: important not to ignore}

In terms of errors of inclusion, it is clear that those who are included tend to be amongst the poor, meaning the approach would increase the targeting efficiency of VUP. However, it is also important to be aware that it is ultimately a rationing tool, and that the errors of exclusion mean that households that are equally worthy (in terms of their poverty levels) will be excluded while their neighbours, who may be very similar, are included.

This has led to PMTs often being viewed as 'lotteries' by households in areas where they are used, as they find it impossible to understand why some are included and some are excluded. ${ }^{13}$ Ultimately any targeting approach is a rationing device, and PMTs may be a more quantitative way to ration, but the quantitative nature does not remove all arbitrariness from the process. For example, different households will be incorrectly 
included/excluded depending on the specific variables included in the model. A technical approach such as the PMT therefore does not mean it is entirely 'fair', and it is always important to ensure that the implications of this exclusion error are well considered. Of course, a wellfunctioning appeals and complaints procedure would be the first port of call for households to raise concerns associated with targeting fairness.

\section{Implications for the community-based approach of Ubudehe and implementation concerns}

In addition to the potential gains in targeting accuracy from applying a PMT/scorecard approach, it is also important to consider how changes would affect community participation in the process and community ownership of and buy-in to the results. In Rwanda, the community involvement has always been a fundamental part of the poverty identification process, and must remain so. PMTs are generally thought of as entirely technical exercises that would not involve any community participation. In practice, however, community participation could be incorporated into a PMT scorecard approach in the following ways:

\section{Communities establish which households should be included in the scorecard.}

This may limit the accuracy of a PMT since legitimately poor households may be excluded from the 'eligible' bottom two categories in the first stage. It depends upon the quality of participation. Similarly, non-eligible households (those that are wealthy by consumption standards) may be categorised in the lowest two categories and be able to claim benefits.

\section{Communities validate the ranking/beneficiaries after} the PMT has been undertaken.

This is the most common approach. Through community validation, errors of exclusion could be minimised and errors of inclusion corrected. This would also support the application of scheme-specific eligibility criteria (for example, availability of household labour in VUP criteria).

\section{The scorecard is administered to communities in} groups rather than at an individual household level.

This may provide some validation of responses and maintains the community tradition of Ubudehe. It is likely that only the short version of the scorecard, without a household roster, can be applied in this way.
Participation may simply improve the accuracy of targeting, or it may also ensure greater ownership and buy-in of the community to the results. In the Rwandan context, both objectives are important: improving targeting accuracy for more optimal allocation of scarce resources and helping to ensure greater ownership of the community, where social cohesion concerns are uppermost.

Of course, the scorecard/PMT would not be implemented in a vacuum: the Ubudehe approach has already been operating and people are familiar with it. The question is whether, given the lack of ownership of current results by community members, a more technical 'black box' approach would be considered an improvement, or whether poor households would feel that the absence of a community poverty ranking excluded them from the process. These questions can only be answered by testing the scorecard in practice.

\section{Conclusions}

In a context of high economic growth and a vision for the future that holds high ambitions for the reduction of poverty, Rwanda has an opportunity to ensure that the benefits accruing to the country are experienced by all members of society. The proper identification of those in need, with appropriate design in targeting of social services and benefits will be key, both to continuing to deliver sustainable graduation from poverty and to ensuring that the poorest are not left behind.

This article has illustrated just how difficult it is to identify the poor/non-poor and how inclusion of households into social programmes is determined by what coverage thresholds are identified - usually a political choice. Poverty targeting and graduation are intimately related, as criteria for one has obvious implications for the other. Furthermore, monitoring poverty identification criteria over time also enables monitoring of graduation trajectories. In theory, applying a simple poverty scorecard may help ensure that more of the poor(est) are classified as such, therefore strengthening Rwanda's Ubudehe approach. Through field testing the scorecard approach we will be able to understand whether the theoretical results presented in this article apply in practice. Field testing will test both how the scorecard could be applied in a community setting and the results of the 
scorecard in practice. It will also seek to understand communities' perceptions of this 'objective' approach and how participation can be incorporated. This hybrid approach promises to provide new insights for the targeting

\section{Notes}

1 The history of the genesis of the Ubudehe system presented in this section draws substantially on the doctoral work of Shah (2011).

2 EICV 2000/01, 2005/06 and 2010/11 analysed in NISR (2012) and World Bank (2013).

3 Net enrolment rate.

4 INS (2006, 2011). Under-five mortality has improved from 196 deaths per 1,000 live births to 76 per 1,000 live births in 2010 .

5 NISR (2014).

6 Thanks to the support of the National Institute of Statistics of Rwanda (NISR), we were basically able to match the survey data with the administrative data, since the Ubudehe database includes most households in the country.

7 The graph does not display results for Ubudehe categories 5 and 6 because they are so infrequent, at less than 1 per cent of the total. For this reason some columns sum to slightly less than 100 per cent.

8 Similar results are available from the authors for a range of other assets.

9 In a wide meta-analysis of the empirical literature, Howe et al. (2008) and Howe et al. (2009) found that asset indices are generally a poor proxy for consumption expenditure. They

\section{References}

Barrientos, A. and Niño-Zarazúa, M. (2011) Social Transfers and Chronic Poverty: Objectives, Design, Reach and Impact, Manchester: Chronic Poverty Research Centre

Berglund, A. (2013) A Local Perspective of the Vision 2020 Umurenge Programme and the Land Tenure Regularisation Programme, www.swedenabroad.com/ .../Government_policies_from_a_local perspective (accessed 12 December 2014)

Coady, D.; Grosh, M. and Hoddinott, J. (2004) 'Targeting Outcomes Redux', World Bank Research Observer 19.1: 61-85

Ensign, M. and Bertrand, W. (2010) RwandaHistory and Hope, Maryland MD: University Press of America

Filmer, Deon and Pritchett, Lant (1998) Estimating Wealth Effects without Expenditure Data literature - on incorporating community participation into a scorecard approach, or incorporating a scorecard approach into a community-based, (more or less) participatory method of socioeconomic categorisation.

perform better in middle-income countries compared to low-income countries, and are a better proxy for consumption in urban rather than rural areas. In the canonical paper on asset measures of poverty, Filmer and Pritchett (1998: 14) found 'reasonably good' coherence between asset quintiles and consumption quintiles, but even here only twothirds of households in the bottom two consumption quintiles were also identified as being in the bottom two quintiles by assets. Similarly, only 56 per cent of households in the richest consumption quintile were also in the top asset quintile, while 13 per cent were identified in the bottom asset quintile.

10 Using the variables lighting_oil, lighting_firewood, lighting_electricity, cooking_charcoal, wall_cement toilet_flush, roof_thatch, and bike.

11 Detailed regression results are available from the authors on request

12 An adjusted R-squared of .635 (meaning that the variables in the regression account for 63.5 per cent of the variation in consumption across households) for the more inclusive list of variables and .603 for the shorter list.

13 See Kidd and Wylde (2011) for further discussion.

\section{or Tears: With an Application to Educational} Enrolments in States of India, World Bank Policy Research Working Paper 1994, Washington DC: World Bank

Howe, L.D.; Hargreaves, J.R. and Huttly, S.R.A. (2008) 'Issues in the Construction of Wealth Indices for the Measurement of SocioEconomic Position in Low-Income Countries', Emerging Themes in Epidemiology 5.3: 1-14

Howe, L.D.; Hargreaves, J.R.; Gabrysch, S. and Huttly, S.R.A. (2009) 'Is the Wealth Index a Proxy for Consumption and Expenditure? A Systematic Review', Journal of Epidemiology and Community Health 63: 871-80

INS (2011) Demographic and Health Survey 2006, Kigali, Rwanda: Institut National de la Statistique Ministère des Finances et de la Planification Économique 
INS (2006) Demographic and Health Survey 2005,

Kigali, Rwanda: Institut National de la Statistique Ministère des Finances et de la Planification Économique

Joseph, Sam (2006) Creating Spaces for Citizen Participation in Self Governance, Poverty Analysis, Local Problem Solving, Sector/District Planning, Kigali: Ministry of Local Government (MINALOG)

Kidd, S. and Wylde, E. (2011) Targeting the Poorest: An Assessment of the Proxy Means Test Methodology, Canberra: AusAID

MINECOFIN (2003) Ubudehe mu Kurwanya Ubukene, Ubudehe to Fight Poverty, Concept Note, Government of Rwanda, Kigali: Ministry of Economics and Finance (MINECOFIN)

MINALOG (2012) 'Draft Harmonisation Paper for the Social Protection Sector', Ministry of Local Government (MINALOG)

NISR (2014) Fourth Population and Housing Census, Rwanda, 2012, Main Indicators Report, Kigali: National Institute of Statistics of Rwanda

NISR (2012) The Evolution of Poverty in Rwanda from 2000 to 2011: Results from the Household Surveys $(E I C V)$, Kigali: National Institute of Statistics of Rwanda

Sabates-Wheeler, R.; Lind, J. and Hoddinott, J. (2013) 'Implementing Social Protection in
Pastoralist Areas: How Local Distribution Structures Moderate PSNP Outcomes in Ethiopia', World Development 50: 1-12

Sentama (2014) Rwanda Civil Society Platform:

Ubudehe Categorisation and its Impact on Citizens' Living Conditions in Rwanda, Illumination Consultancy and Training Centre Ltd, www.rcsprwanda.org/spip.php?article 350 (accessed 9 February 2015)

Shah, A. (2013) 'Participatory Statistics, Local Decision-making, and National Policy Design: Ubudehe Community Planning in Rwanda', Who Counts? The Power of Participatory Statistics: 49-63

Shah, A. (2011) 'The Paradox of "Hidden Democracy" in Rwanda: The Citizens' Experience of Ubudehe', unpublished thesis, Queen Elizabeth House Wolfson College, Oxford University, Oxford

VUP (Vision 2020 Umurenge Programme) (2011) Annual Report 2009/2010, Kigali: Government of Rwanda

World Bank (2013) 'Focus Section: Rwanda's Pathway Out of Poverty', Rwanda Economic Update 4: 31-60 